\title{
Synaptic Regulation of Action Potential Timing in Neostriatal Cholinergic Interneurons
}

\author{
Ben D. Bennett and Charles J. Wilson \\ Department of Anatomy and Neurobiology, University of Tennessee, Memphis, Tennessee 38163
}

Action potentials in neostriatal cholinergic interneurons recorded in vivo are triggered by summation of two or three discrete synaptic depolarizations (Wilson et al., 1990). The ability and precision with which EPSPs and IPSPs regulate action potential timing was therefore investigated in vitro. Cholinergic interneurons were identified on the basis of morphological and electrophysiological characteristics in neostriatal slices taken from 2- to 3-week-old postnatal rats recorded at 24-26 ${ }^{\circ} \mathrm{C}$.

During periods of induced regular firing, intrastriatal stimuli were used to evoke pharmacologically isolated monosynaptic AMPA receptor-mediated EPSPs or GABA $_{A}$ receptor-mediated IPSPs. EPSPs evoked during the interspike interval (ISI) produced a phase-dependent decrease in the ISI, whereas IPSPS produced a phase-independent prolongation of the ISI. Injection of brief depolarizing currents mimicked the action of EPSPS and revealed an alteration in the input resistance during the ISI. In contrast to IPSPS, the ability of brief hyperpolarizing current injections to delay spike generation was phase-dependent. After blockade of GABAergic and glutamatergic synaptic transmission, stimuli failed to produce a detectable conductance change but could still prolong the subsequent ISI primarily through a D1 dopamine receptor-mediated enhancement of the afterhyperpolarization (AHP).

Hence, EPSPs are ideally suited to provide a precise regulation of spike timing in cholinergic cells, whereas IPSPs are more likely to influence the overall level of excitability. The D1mediated modulation of the AHP may contribute to the prolonged ISI seen in tonically active neurons in vivo in monkeys trained to respond to a sensory cue.

Key words: neostriatum; basal ganglia; $A M P A ; G A B A_{A}$; neuromodulation; firing; TANs; $D 1$ receptors
Intracellular recordings in vivo have revealed that giant neostriatal interneurons receive a constant barrage of depolarizing synaptic input (Wilson et al., 1990). In contrast to the spiny projection neurons, unitary synaptic potentials are readily discerned in the giant cells, and summation of only two or three such potentials is sufficient to trigger an action potential (Wilson, 1993). Hence, these depolarizing potentials appear to be instrumental not only in the generation of the tonic irregular firing pattern observed in giant cells in vivo (Wilson et al., 1990) but also in the precise timing of action potential generation.

The giant cells exhibit exactly the same morphological and physiological characteristics as identified cholinergic interneurons (Kawaguchi, 1993; Götz et al., 1997), which have been indirectly demonstrated to be the tonically active neurons (TANs) recorded in extracellular unit studies. TANs are sparse and unresponsive to pallidal stimulation, indicating that they represent a population of neostriatal interneurons (Kimura et al., 1990), and giant cells are tonically active, as are the TANs, both exhibiting wide action potentials (Kimura et al., 1990; Wilson et al., 1990; Aosaki et al., 1994b). Thus, it seems very likely that the TANs and the cholinergic interneurons are the same population of cells.

The importance of the firing pattern in giant cells is illustrated by the fact that in contrast to spiny cells, TANs primarily respond to sensory stimuli, which serve as a cue to perform a learned motor task (Crutcher and DeLong, 1984; Kimura et al., 1984;

\footnotetext{
Received June 15, 1998; revised July 30, 1998; accepted Aug. 8, 1998.

This work was supported by National Institutes of Health Grants NS26473 and NS37760. We thank Dr. Edward Stern for his many useful comments regarding this manuscript.

Correspondence should be addressed to B. D. Bennett, Department Anatomy and Neurobiology, 875 Monroe, University of Tennessee, Memphis, TN 38163

Copyright (C) 1998 Society for Neuroscience $0270-6474 / 98 / 188539-11 \$ 05.00 / 0$
}

Liles, 1985; Schultz and Romo, 1988; Hikosaka et al., 1989; Apicella et al., 1991; Aosaki et al., 1994b; Kimura et al., 1996), exhibiting a pause in their tonic irregular firing pattern in response to the sensory cue. Recent data indicate that there is an increase in the proportion of responding TANs in parallel with the acquisition of the learned movement (Aosaki et al., 1994b; Graybiel et al., 1994) and that an intact dopaminergic input is required for the pause response (Aosaki et al., 1994a; Watanabe and Kimura, 1998). These findings have led to the suggestion that TANs perform a central role in motor learning within the neostriatum (Graybiel et al., 1994; Aosaki et al., 1995) and further suggest that it is the pause in tonic firing that is the critical feature of such learning.

Hence, the intracellular data are suggestive that it is the precise timing of action potentials that are important (Wilson et al., 1990), whereas the extracellular data indicate that it is a pause in the background activity of TANs, which encodes information (Graybiel et al., 1994; Aosaki et al., 1995). The role of EPSPs and IPSPs in regulating spike timing in cholinergic neurons was therefore investigated in this study to provide insight into how precisely excitatory and inhibitory synaptic inputs can pattern the output from these cells and to also address whether evoked release of dopamine could modulate spike timing through the activation of D1 or D2 receptors.

\section{MATERIALS AND METHODS}

Slice preparation. Standard techniques were used for the preparation of slices for recording. Briefly, Sprague Dawley rats of either sex, aged 2-3 weeks, were deeply anesthetized with ketamine-xylazine and perfused transcardially with $\sim 10 \mathrm{ml}$ of ice-cold modified artificial CSF (ACSF) containing (in mM): sucrose, 230; KCl, 2.5; $\mathrm{NaH}_{2} \mathrm{PO}_{4}, 1.25 ; \mathrm{CaCl}_{2}, 0.5$; $\mathrm{MgSO}_{4}, 10$; and glucose, 10 . The brain was rapidly removed, blocked in 
either the coronal or sagittal plane, glued to the stage of a Vibroslicer (World Precision Instruments, Sarasota, FL), and immersed in ice-cold modified ACSF. Sections through the neostriatum were cut at a thickness of $300 \mu \mathrm{m}$ and then transferred to a holding chamber where they were completely submerged in ACSF containing (in mM): $\mathrm{NaCl}, 126 ; \mathrm{KCl}, 2.5$; $\mathrm{NaH}_{2} \mathrm{PO}_{4}, 1.25 ; \mathrm{CaCl}_{2}, 2 ; \mathrm{MgSO}_{4}, 2$; and glucose, 10 . This solution was continuously bubbled with $95 \% \mathrm{O}_{2}$ and $5 \% \mathrm{CO}_{2}$ and was maintained at room temperature $\left(24-26^{\circ} \mathrm{C}\right)$. Slices were kept in the holding chamber for at least $1 \mathrm{hr}$ before recording.

Visualized recording. Individual slices were transferred to the recording chamber and were continuously perfused $(2-3 \mathrm{ml} / \mathrm{min})$ with oxygenated ACSF at room temperature for the duration of the experiment. A $40 \times$ water immersion objective (Axioskop; Zeiss, Oberkochen, Germany) was used to examine the slice using standard infrared differential interference contrast (IR-DIC) video microscopy using the method of Stuart et al. (1993). The slice was scanned to locate neurons with large somata, which were preferentially targeted. Once a candidate neuron had been located, a stimulating electrode was placed in the neostriatum 200-500 $\mu \mathrm{m}$ from the cell of interest, but no particular orientation was used because all placements were equally effective. Stimulating electrodes were either monopolar patch pipettes (10-20 $\mu \mathrm{m}$ tip diameter) filled with ACSF or bipolar tungsten electrodes (World Precision Instruments). Recordings were made with patch pipettes prepared from thin-wall borosilicate glass (Warner Instrument Co., Hamden, CT) on a P-87 Flaming/Brown electrode puller (Sutter Instrument Co., Novato, CA). Pipettes were filled with a solution containing: $\mathrm{K}-\mathrm{MeSO}_{4}, 131 \mathrm{~mm}$; $\mathrm{MgCl}_{2}, 1 \mathrm{~mm}$; $\mathrm{CaCl}_{2}, 0.1 \mathrm{~mm}$; HEPES, $10 \mathrm{~mm}$; EGTA, $1 \mathrm{~mm}$; Na-GTP, $0.4 \mathrm{~mm}$; Mg-ATP, $2 \mathrm{~mm}$; biocytin, $5 \mathrm{~mm}$; pH 7.3; and 280-300 mOsm, yielding tip resistances of 5-8 $\mathrm{M} \Omega$. Series resistance (15-30 M $\Omega$ ) was monitored throughout the recording, and neurons exhibiting $>25 \%$ change were rejected. Voltage errors attributable to series resistance and the liquid junction potential were subtracted off-line. In some instances in which the reversal potential of EPSCs was sought, the electrode solution was modified with substitution of equimolar $\mathrm{Cs}-\mathrm{MeSO}_{3}$ for $\mathrm{K}-\mathrm{MeSO}_{4}$ and inclusion of QX-314 $(5 \mathrm{~mm})$. In recordings in which the reversal potential of evoked IPSCs was determined, K-gluconate was used in place of $\mathrm{K}-\mathrm{MeSO}_{4}$, and $\mathrm{CaCl}_{2}$ and EGTA were used at a concentration of 1 and $10 \mathrm{~mm}$, respectively. Recordings were made in the whole-cell configuration using an Axopatch 200A amplifier and pClamp 6.0 (Axon Instruments, Foster City, CA). Signals were filtered at $5 \mathrm{kHz}$ and digitized at $\geq 20 \mathrm{kHz}$ (Digidata 1200; Axon Instruments).

Drugs and stimulation. Slices were perfused with $50 \mu \mathrm{M}( \pm)-2$-amino5-phosphonopentanoic acid (APV) (Research Biochemicals, Natick, MA), $20 \mu \mathrm{M}$ 6,7-dintroquinoxaline-2,3-dione (DNQX) (Research Biochemicals), and/or $10 \mu \mathrm{M}(-)$-bicuculline methiodide (BMI) (Research Biochemicals) to isolate AMPA or $\mathrm{GABA}_{\mathrm{A}}$ receptor-mediated synaptic inputs. In a subsequent series of experiments, $10 \mu \mathrm{M} \mathrm{SCH}-23390$ (Research Biochemicals), a D1 dopamine receptor antagonist, was applied. For pharmacological and current-voltage characterization of synaptic inputs, neurons were voltage clamped, and single stimuli $(50-400 \mu \mathrm{A}$, $50-200 \mu \mathrm{sec}, 0.2 \mathrm{~Hz}$ ) were applied to the neostriatum to evoke monosynaptic EPSCs or IPSCs. Square wave somatic current injections (20-60 pA, $600 \mathrm{msec}, 0.2 \mathrm{~Hz}$ ) were used to generate episodes of regular spiking, with a relatively stationary interspike interval (ISI) (see Fig. 2). Stimuli were applied to evoke an EPSP or IPSP at various points during the ISI to allow determination of the effect of AMPA and $\mathrm{GABA}_{\mathrm{A}}$ receptor-mediated synaptic inputs upon spike timing. The intensity and duration of the stimuli used for evoking EPSPs and IPSPs is described above and was used because it gave rise to synaptic potentials that were of comparable amplitude to those observed in vivo $(\sim 1-5 \mathrm{mV})$. Brief somatic current injections $( \pm 150 \mathrm{pA}, 10 \mathrm{msec}$ or $+0.5 \mathrm{nA},-1.0 \mathrm{nA}, 1$ $\mathrm{msec}$ ) were used during induced regular single-spiking to determine whether the effects of EPSPs and IPSPs could be mimicked by equivalent voltage perturbations at the soma and to determine whether there were detectable changes in the input resistance $\left(R_{\text {in }}\right)$ during the ISI.

Data analysis. Data were analyzed using Axograph 3.0 (Axon Instruments), Kaleidagraph 3.0.5 (Synergy Software, Reading, PA), and Mathematica 3.0 (Wolfram Research Inc., Champaign, IL). Data were pooled to look for population effects. In experiments in which the effects of EPSPs and IPSPs were examined, the ISI for each epoch was expressed as a proportion of the mean control ISI for the same cell (see Fig. 4), and this proportion is referred to as the normalized ISI throughout. Similarly, the time from the first spike to the stimulus was also normalized to give phase relative to the mean control ISI (see Fig. 4). The amplitude of individual voltage deflections produced by individual EPSPs, IPSPs, or intrasomatic current pulses was expressed as a proportion of the mean amplitude of all EPSPs, IPSPs, or voltage deflections produced by current pulses measured during the ISI for each neuron (see Fig. 4). The data used for the analysis of alterations in the ISI produced by IPSPs, EPSPs, or current injections were first examined using the KolmogorovSmirnov statistic for intrinsic hypotheses to confirm that the data were normally distributed. In all instances, $p<0.05$, and the data were therefore considered to be normal. Consequently, the $95 \%$ confidence interval was determined, and the points which lay outside this interval were deemed to be significant $(p<0.05)$. For correlations, a linear regression was fit, the $r$ value was converted to a $t$ value, and significance was assigned when $p<0.001$. A two-way ANOVA was used to determine whether blockade of D1 dopamine receptors produced a significant $(p<$ 0.01 ) effect. All other values are given as mean \pm SD throughout.

Histochemical processing of filled cells. After termination of recording, slices were fixed by immersion in $2.5 \%$ paraformaldehyde in $0.1 \mathrm{M}$ phosphate buffer, $\mathrm{pH} 7.4$, and were then processed either after resectioning to a thickness of $70 \mu \mathrm{m}$ or as whole mounts, using standard histochemical techniques (Horikawa and Armstrong, 1988). The biocytincontaining neurons were post-fixed with osmium, dehydrated, and mounted on slides. Synthetic projection micrographs of filled neurons were prepared using the method of Agard et al. (1989).

\section{RESULTS}

\section{Morphological and electrophysiological identification of neostriatal cholinergic interneurons}

Neurons were initially selected for recording on the basis of their somatodendritic morphology as observed in the slice under IRDIC optics (Kawaguchi, 1992). Cells possessing large somata and thick primary dendrites were preferentially targeted (Fig. $1 A$ ). In these cells, depolarization elicited repetitive regular spiking (Fig. $1 C)$, with relatively broad action potentials $(>1 \mathrm{msec}$ width at half-amplitude) (Fig. 1D), which were followed by a largeamplitude long-duration afterhyperpolarization (AHP) (Fig. 1C). Injection of negative current produced an initial hyperpolarization, followed by a subsequent sag in the membrane potential (Fig. 1E). Subthreshold positive current injections produced a depolarizing ramp potential (Fig. $1 E$ ). Examination of biocytinfilled neurons revealed that the thick primary dendrites branched to form secondary and higher order small-diameter dendrites (Fig. $1 B$ ), which terminated in fine tufts. These morphological and physiological features are characteristic of neostriatal cholinergic interneurons (Bolam et al., 1984; Wainer et al., 1984; Phelps et al., 1985; DiFiglia, 1987; Wilson et al., 1990; Kawaguchi, 1992, 1993; Plenz and Aertsen, 1996; Götz et al., 1997), and only cells in which both of the electrical and morphological features were confirmed as those of cholinergic interneurons were included for further analysis.

To study the influence of synaptic inputs on action potential timing, episodes of regular spiking were induced by injecting small-amplitude (20-60 pA, $600 \mathrm{msec}, 0.2 \mathrm{~Hz})$ depolarizing current pulses (Figs. $1 C, 2 B$ ). The injected currents were adjusted to cause the cells to fire at approximately the same frequency (2-10 $\mathrm{Hz}$ ) as that observed for cholinergic interneurons in vivo (Kimura et al., 1990; Wilson et al., 1990) and were used because although cholinergic neurons fired spontaneously in the majority of cases $(>80 \%)$ (Fig. 2A), ISI fluctuated markedly during periods of spontaneous activity. Somatic current injections generated episodes of firing (Fig. 2), with relatively stationary ISIs, which therefore allowed the effect of isolated EPSPs or IPSPs on spike timing to be examined.

\section{Pharmacological and current-voltage characterization of excitatory inputs to cholinergic cells}

In the presence of APV $(50 \mu \mathrm{M})$ and BMI $(10 \mu \mathrm{M})$, intrastriatal stimulation $(100-300 \mu \mathrm{A}, 50-100 \mu \mathrm{sec}, 0.2 \mathrm{~Hz})$ evoked a fast 

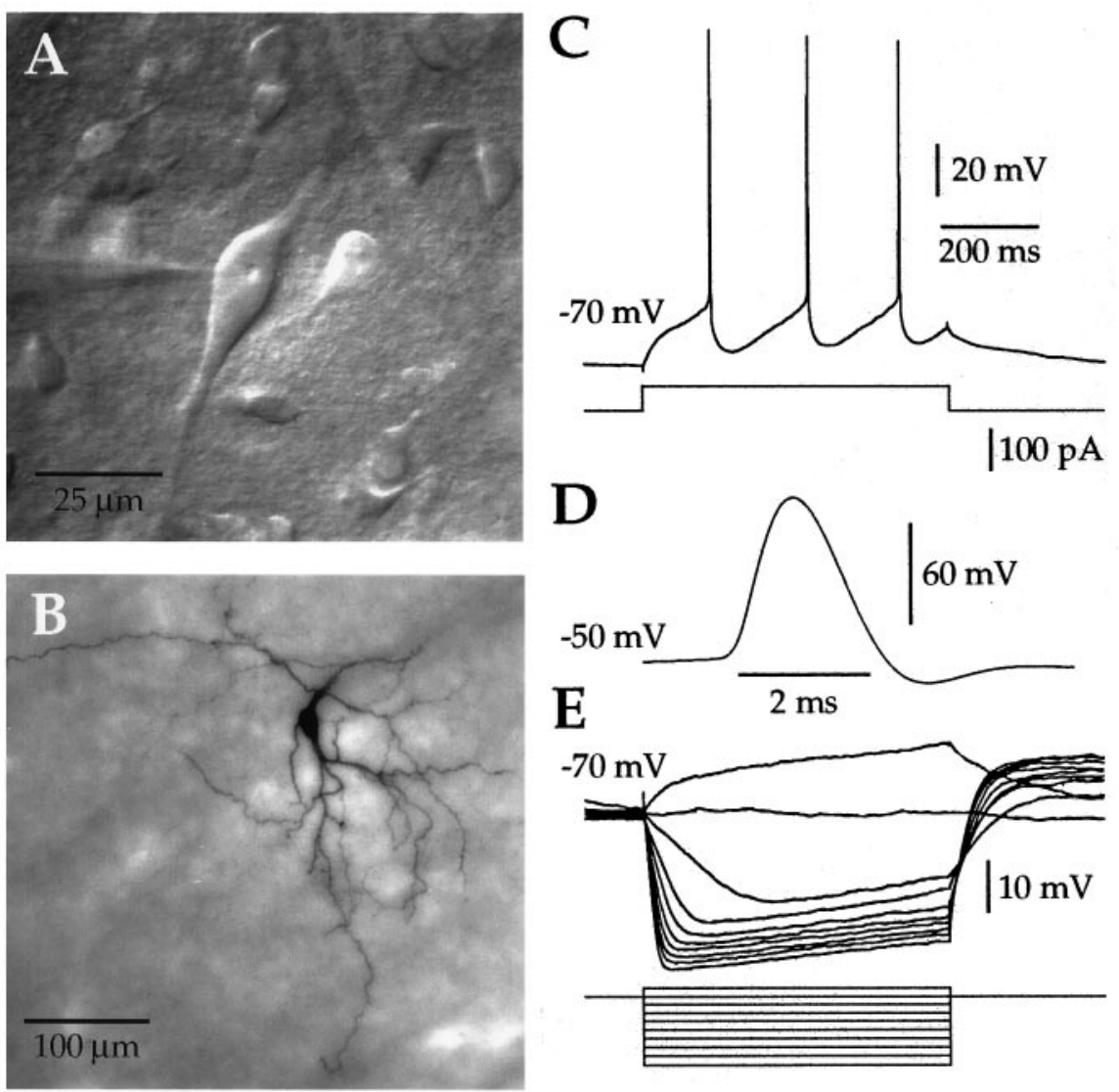

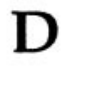

\section{$-$}

\section{E}

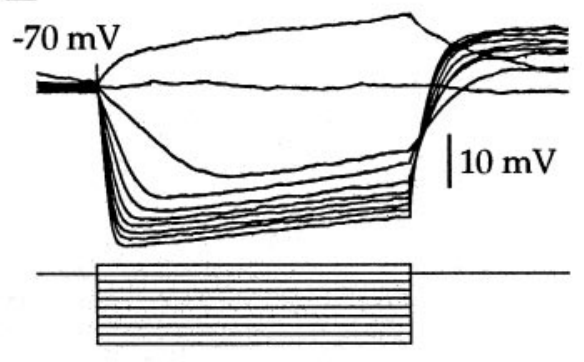

Figure 1. Morphological and physiological characterization of neostriatal cholinergic interneurons. $A$, An IR-DIC image of a neostriatal slice illustrating the characteristic appearance of giant interneurons. The large soma and thick primary dendrites are stereotypical features of cholinergic cells. $B$, Synthetic projection micrograph of a giant cell filled with biocytin in vitro and subsequently stained using standard techniques. In addition to the morphological features visible under IR-DIC optics, the secondary and higher order dendrites can be seen to branch, becoming fine-diameter structures. $C$, Depolarizing somatic current injection elicited regular spiking with each action potential, followed by a large-amplitude long-duration AHP. $D$, Action potentials were slow, with a width at half-amplitude always in excess of $1 \mathrm{msec}$. $E$, Injection of negative current caused an initial hyperpolarization, followed by a sag in the membrane potential. Subthreshold positive current injection produced a depolarizing ramp. These morphological and physiological features are characteristic of neostriatal cholinergic interneurons. In $C-E$, the initial membrane voltage is indicated to the left of each trace. Time and current calibration for $E$ are the same as in $C$. inward current (Fig. 3). The EPSCs were considered to be monosynaptic because they were evoked at short latency from the time of the stimulus $(\sim 2-3 \mathrm{msec}$ ) (Fig. $3 A, C)$ and the latency was constant over a range of stimulus intensities. The amplitude of the evoked EPSCs were voltage-dependent (Fig. $3 A$ ), and in the neuron shown in Figure $3 B$, reversed polarity at approximately $-5 \mathrm{mV}$. Overall, evoked EPSCs exhibited a mean reversal potential of $+1.1 \pm 9.0 \mathrm{mV}(n=9)$. The stimulus intensities described above were used because they evoked EPSPs that were of comparable amplitude to spontaneous depolarizing potentials observed in vivo (1-5 mV) (Wilson et al., 1990). The mean amplitude of the evoked EPSCs was $120.6 \pm 64.1$ and $102.1 \pm 54.8 \mathrm{pA}$ at -65 and $-55 \mathrm{mV}$, respectively, yielding a slope conductance of $1.85 \mathrm{nS}$. At a holding potential of $-65 \mathrm{mV}$, bath application of DNQX $(20 \mu \mathrm{M})$ completely blocked the evoked current (Fig. $3 C, D)$, confirming that intrastriatal stimulation in the presence of APV and BMI evokes an AMPA receptor-mediated EPSC. Complete blockade of the evoked EPSC with DNQX $(20 \mu \mathrm{M})$ was observed in eight of eight neurons. In an additional seven neurons, the kinetics of the evoked EPSCs were examined from recordings made using the cesium-based electrode solution described in Materials and Methods. Neurons were held at $-70 \mathrm{mV}$, and stimuli in the same range as those described above were delivered, evoking fast inward currents with a peak amplitude of $117.0 \pm 35.7 \mathrm{pA}$, a $10-90 \%$ rise time of $2.1 \pm 1.3 \mathrm{msec}$, a half-width of $8.1 \pm 2.6 \mathrm{msec}$, and a $90 \%$ decay time of $18.8 \pm 8.4$ msec. The early phase of the decay of the evoked EPSCs was well fitted by a single exponential, yielding a time constant of $7.2 \pm 1.7$ msec. There was a small residual $(<10 \%)$, which could be fit by an additional very slow exponential decay, but insufficient data points were sampled to allow confidence in the second time constant.

To facilitate comparison of the influence of synaptic EPSPs, IPSPs, and intrasomatic current injections on spike timing across a population of neurons, the ISIs were normalized (as described below) to account for differences in firing rate. The ISI was only measured in cases during which the $600 \mathrm{msec}$ current injection evoked either two or three spikes, i.e., for trials in which mean firing rates were $3.3-5.0 \mathrm{~Hz}$. For each neuron subjected to a particular protocol, measurements of the ISI when no stimulus was delivered were made to provide a mean control ISI value (Fig. 4A). The ISI for each epoch in which a synaptic stimulus or current pulse was delivered was measured (Fig. 4A) and expressed as a proportion of the mean control ISI for that cell. The interval between the first spike and the stimulus or current pulse was also measured (Fig. $4 A$ ) and expressed as a proportion of the mean control ISI. Finally, the amplitude of the EPSP, IPSP, or voltage deflection produced by the current injection was measured for all such stimuli falling between two spikes (Fig. 4B), and the mean was calculated. The peak amplitude of each EPSP, IPSP, or voltage deflection produced by the current injection was then expressed as a proportion of the mean value.

\section{AMPA receptor-mediated EPSPs exhibit phase- dependent effects on spike timing}

Regular single spiking was induced by intrasomatic depolarizing current injection (20-60 pA, $600 \mathrm{msec}, 0.2 \mathrm{~Hz})$. Intrastriatal stimulation was applied in the presence of APV and BMI to evoke AMPA receptor-mediated EPSPs at various times during the ISI (Fig. $5 A$ ). Stimulating currents $(221 \pm 64 \mu \mathrm{A}, 93 \pm 35$ 


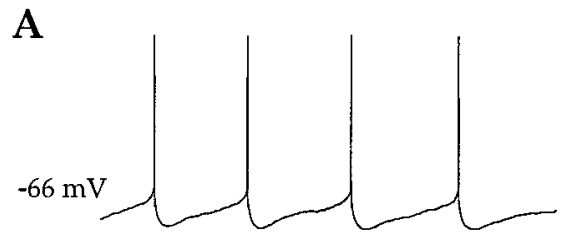

B
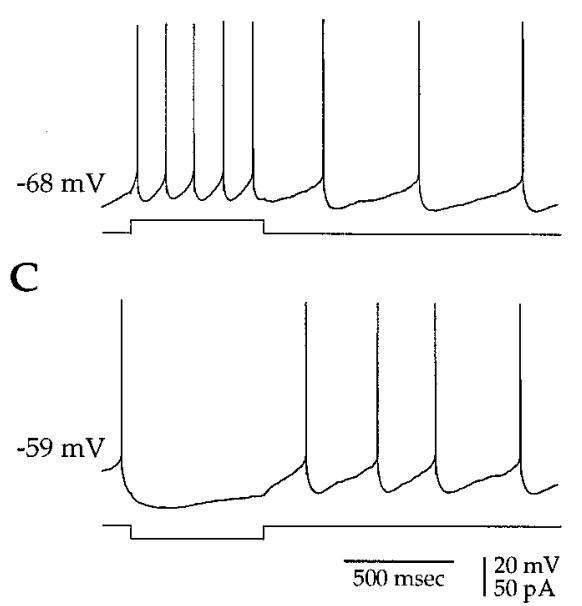

Figure 2. Small-amplitude current injections induce regular spiking in spontaneously active cholinergic neurons. $A$, The majority $(>80 \%)$ of cholinergic neurons were spontaneously active in vitro. $B$, Depolarizing somatic current injection $(20 \mathrm{pA}, 600 \mathrm{msec}, 0.2 \mathrm{~Hz})$ was used to elicit regular spiking with a stationary interspike interval. $C$, Hyperpolarizing current injection $(-20 \mathrm{pA})$ caused a cessation in spontaneous firing, illustrating that the spiking in cholinergic neurons was readily controlled by small-amplitude current injections. The initial membrane potential is indicated to the left of each trace.

$\mu \mathrm{sec})$ were adjusted to generate EPSP amplitudes between 1-5 $\mathrm{mV}(2.95 \pm 0.73 \mathrm{mV} ; n=7)$. A shortening of the ISI was observed when EPSPs were evoked late in the ISI, as expected for depolarizing synaptic inputs, but stimuli that were presented before the first spike of a pair caused prolongation of the subsequent ISI (see below) (Fig. 5A). Examination of all epochs from this cell (Fig. $5 B$ ) revealed that stimuli evoked before the first spike consistently caused an increase in the subsequent ISI, whereas EPSPs in the first half of the ISI were progressively less effective in altering the ISI, and EPSPs in the second half of the ISI were excitatory, as expected, triggering spikes in one of two ways: either the EPSPs crossed action potential threshold during the rising phase or peak of the depolarization and triggered a spike directly (Fig. $5 A$ ), or the initial depolarization was insufficient to make the neuron fire immediately, but the EPSP persisted and crossed threshold some tens of milliseconds later (Figs. $4 B, 5 A, 6 E)$.

The stimulus produced a significant decrease in ISI when delivered $>0.4$ ISI $(\sim 80-120 \mathrm{msec})$ after the first spike (Fig. $5 C)$. Insight into the phase dependence of the ability of EPSPs to shorten the ISI was provided by examination of the amplitude of EPSPs during various phases of the ISI, which revealed a significant $(r=0.382$; df $=206 ; p<0.001)$ positive correlation (slope, 0.516 ) between these parameters (Fig. $5 D$ ). Because the driving force for AMPA receptor-mediated synaptic currents is decreasing as the neuron becomes more depolarized, a likely explanation for the increase in EPSP amplitude during the ISI is a change in $R_{\text {in }}$ of the neuron. Additionally, some subthreshold EPSPs could
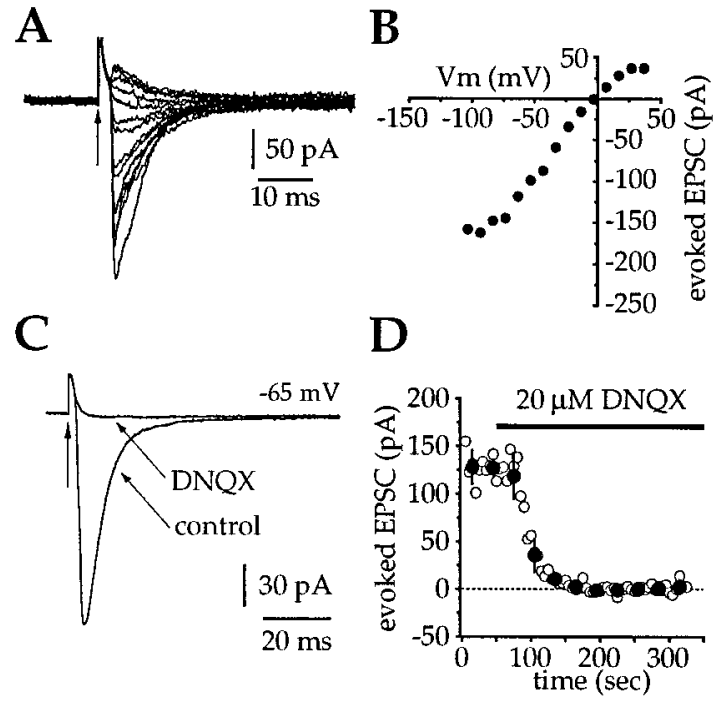

Figure 3. Current-voltage and pharmacological characterization of excitatory synaptic inputs to cholinergic cells. $A$, A series of EPSCs evoked by intrastriatal stimulation after blockade of NMDA and $\mathrm{GABA}_{\mathrm{A}}$ receptors at holding potentials between -105 to $+35 \mathrm{mV}$. Vertical arrows in $A$ and $C$ indicate the stimulus artifact. $B$, Current-voltage plot for the same cell in $A$ revealed a reversal potential of approximately $-5 \mathrm{mV}$. Each point is the mean peak amplitude of three EPSCs evoked at each of the holding potentials. $C$, At $-65 \mathrm{mV}$, bath application of DNQX $(20 \mu \mathrm{M})$ completely blocked the evoked inward current. Traces are averages of 25-30 individual trials. $D$, Time series for the effect of bath application of DNQX on evoked EPSC amplitude from the same cell in C (open circles, individual EPSCs; filled circles, mean \pm SD of six sequential EPSCs). These data illustrate that intrastriatal stimulation in the presence of APV and BMI evokes a solely AMPA receptor-mediated inward current.

persist and trigger spikes tens of milliseconds after the peak of the synaptic depolarization (Figs. $4 B, 5 A, 6 E$ ), indicating that activation of a voltage-dependent subthreshold inward current probably also influences the ability of EPSPs to trigger spikes during the ISI.

\section{Depolarizing somatic current injections mimic the excitatory actions of EPSPs and reveal alterations in Rin during the ISI}

Brief depolarizing current injections were used to investigate whether the effects of AMPA receptor-mediated EPSPs could be mimicked by equivalent voltage perturbations at the soma and whether there were detectable changes in the $R_{\mathrm{in}}$ during the ISI (Fig. 6). Injection of positive current pulses $(+0.5 \mathrm{nA}, 1 \mathrm{msec}$ or $+150 \mathrm{pA}, 10 \mathrm{msec})$ during the ISI elicited a mean voltage deflection of $3.99 \pm 0.35 \mathrm{mV}(n=6)$ and $7.29 \pm 2.29 \mathrm{mV}(n=5)$, respectively. Current pulses delivered before the first spike in a pair did not reproduce the effects of intrastriatal stimulation (Figs. 5, 6, compare $A-C, A-C$ ), indicating that somatic depolarization was unnecessary or insufficient to cause the prolongation of the ISI observed when intrastriatal stimuli were delivered before the first spike or during the early phase of the ISI. However, the subsequent ISI was increased when the current injection was completely coincident with the action potential (Fig. 6B,C), perhaps as a consequence of a prolonged depolarization during the spike causing increased calcium entry and subsequent enhancement of the spike AHP. The excitatory effects of EPSPs were mimicked by depolarizing current injections that were delivered during the ISI (Fig. $6 A, B$ ). These effects were consistent 
A
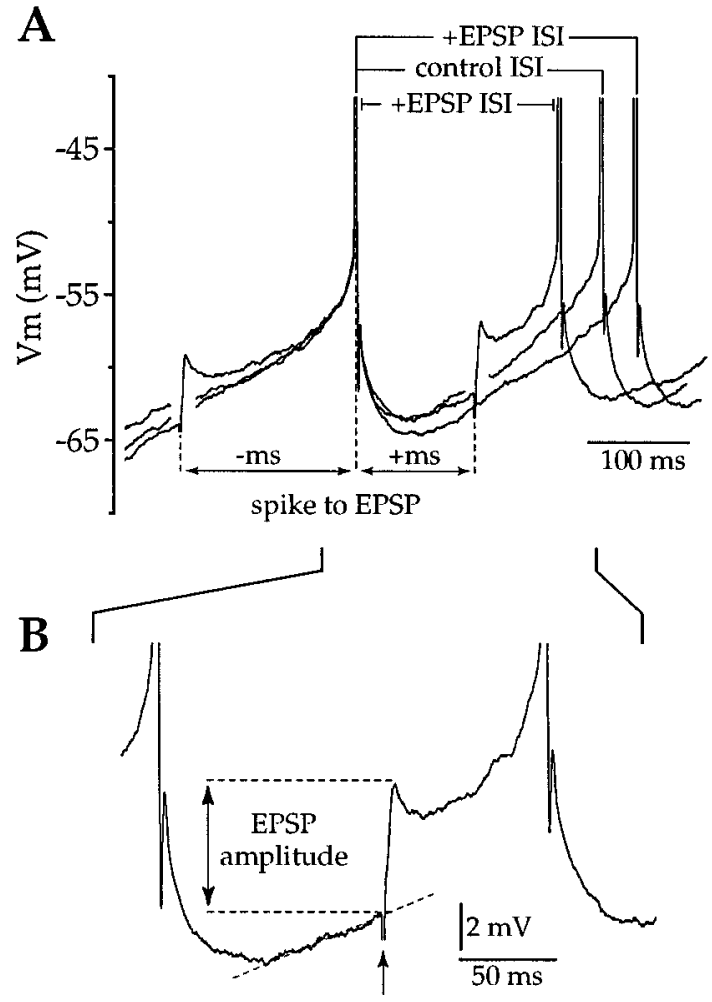

Figure 4. Measurements made to determine the phase dependence of the amplitude of postsynaptic potentials and voltage deflections produced by current injections and their effects on ISI. In this example, the effects of evoked EPSPs on spike timing are illustrated, but analogous measurements were made for all experiments in which the effect of EPSPs, IPSPs, and current injections on spike timing were investigated. $A$, The ISI was measured for all epochs in which there was no synaptic stimulus, and a mean control ISI was calculated for each neuron. The ISI was then measured for each epoch in which an EPSP was evoked, and the value was expressed as a proportion of the mean control ISI. The time from the first spike to the stimulus was measured and expressed as a proportion of the mean control ISI to give the phase. The phase had a negative value when the EPSPs were evoked before the first spike and a positive value when they fell after the first spike. $B$, An enlargement of the area indicated in $A$ illustrates how the amplitudes of the EPSPs were measured. In an individual cell, the amplitude of all EPSPs evoked during the ISI were measured, the mean was calculated, and individual EPSPs were then expressed as a proportion of the mean. Note that in this example, the EPSP that occurs during the ISI does not trigger a spike immediately but causes a depolarization which persists, causing the cell to fire $>50$ msec after the stimulus, whereas the EPSP triggered before the first spike has a prolonged time course but decays back to baseline before the cell spikes.

across the population of neurons tested $(n=12)$, with a significant decrease in the ISI when positive currents were delivered at $>0.3$ ISI $(\sim 60-90 \mathrm{msec})$ after the first spike (Fig. $6 B, C)$. The similarity in the phase dependence of the excitatory effects of EPSPs and depolarizing current injections on influencing spike timing prompted an examination of the changes in $R_{\text {in }}$ during the ISI. The amplitude of the voltage deflection produced by intrasomatic current injection changed dramatically during the ISI (Fig. 6D), revealing a profound alteration in the apparent $R_{\text {in }}$ (slope, $0.790 ; r=0.729$; df $=451 ; p<0.001$ ). This observation provides an explanation for the relatively sudden transition of EPSPs and positive current injections from early ineffective inputs to late highly effective inputs in their ability to influence spike timing. In addition to changes in $R_{\text {in }}$, the ability of sub- threshold positive current injections to shorten the ISI was also affected by the recruitment of a voltage-dependent subthreshold regenerative current. In an analogous manner to that observed with EPSPs (Figs. 4B, 5A, 6E), subthreshold depolarizing current injections, which did not trigger spikes directly, could also shorten the ISI by producing a depolarization which persisted, causing the cell to fire tens of milliseconds after the initial peak (Fig. 6F). These data further support the notion that subthreshold membrane nonlinearities, as well as changes in $R_{\mathrm{in}}$, are responsible for determining at what point during the ISI depolarizing inputs become effective in altering spike timing.

\section{Pharmacological and current-voltage characterization of inhibitory inputs to cholinergic cells}

To examine the effects of inhibitory synaptic inputs on spike timing, a pharmacological isolation of $\mathrm{GABA}_{\mathrm{A}}$ receptormediated currents was performed in an analogous manner to that described above for AMPA inputs. Slices were bathed with APV $(50 \mu \mathrm{M})$ and DNQX $(20 \mu \mathrm{M})$ to block NMDA and AMPA receptors, respectively, and intrastriatal stimulation (100-400 $\mu \mathrm{A}, 60-200 \mu \mathrm{sec}, 0.2 \mathrm{~Hz}$ ) under these conditions evoked an outward current at $-70 \mathrm{mV}$ (Fig. 7). The stimulus intensities described above were used because they evoked IPSPs in current clamp that were of comparable amplitude (but opposite polarity) to spontaneous depolarizing potentials observed in vivo (1-5 mV) (Wilson et al., 1990). However, it was only possible to evoke IPSCs in $\sim 10 \%$ of cholinergic cells using the intensity and duration of stimuli described above, irrespective of the location of the stimulating electrode. In cells in which IPSCs could be elicited, the mean amplitude of evoked IPSCs was $19.0 \pm 20.7$ and $29.5 \pm 25.3 \mathrm{pA}$ at -70 and $-60 \mathrm{mV}$, respectively, yielding a slope conductance of $1.05 \mathrm{nS}$. The current-voltage relationship for the evoked IPSC for the neuron illustrated in Figure 7, $A$ and $B$, gave a reversal potential of approximately $-88 \mathrm{mV}$, which is close to the chloride equilibrium potential predicted by the Nernst equation. Overall, the outward current reversed at $-87.0 \pm 7.2$ $\mathrm{mV}(n=5)$ when the neurons were recorded with a K-gluconate solution containing $4 \mathrm{~mm}\left[\mathrm{Cl}^{-}\right]_{\mathrm{i}}$. Confirmation that these evoked synaptic currents were caused by chloride flux and, more specifically, from activation of $\mathrm{GABA}_{\mathrm{A}}$ receptors was provided by the complete and reversible blockade of the evoked IPSC by application of $10 \mu \mathrm{M}$ BMI (Fig. 7C,D). Bicuculline-sensitivity was confirmed in eight of eight neurons. In the subsequent experiments, the electrode was filled with the $\mathrm{K}-\mathrm{MeSO}_{4}$ solution described in Materials and Methods, which contained a lower chloride concentration $(2.2 \mathrm{~mm})$, providing a larger driving force for $\mathrm{GABA}_{\mathrm{A}}$ receptor-mediated synaptic currents.

In five additional cases, the kinetics of the evoked IPSCs were examined from recordings made using the cesium-based electrode solution described in Materials and Methods. Stimuli in the same range as those described above were delivered while the neurons were clamped at $-10 \mathrm{mV}$. Evoked outward currents exhibited a peak amplitude of $65.5 \pm 14.9 \mathrm{pA}$, a $10-90 \%$ rise time of $4.8 \pm$ $2.6 \mathrm{msec}$, a half-width of $52.6 \pm 14.2 \mathrm{msec}$, and a $90 \%$ decay time of $227.4 \pm 78.9 \mathrm{msec}$. The early phase of the decay of the evoked IPSCs was well fitted by a single exponential, yielding a time constant of $45.8 \pm 7.5 \mathrm{msec}$. There was a small residual $(<10 \%)$ that could be fit by an additional very slow exponential decay, but insufficient data points were sampled to allow confidence in the second time constant. 
Figure 5. Intrastriatal stimulation produces biphasic effects on spike timing. $A$, EPSPs were evoked at various times before and during the ISI to determine the effects of excitatory synaptic potentials on spike timing. EPSPs that were evoked before the first spike appeared to cause an increase in the subsequent ISI, whereas EPSPs evoked late in the ISI shortened the time between spikes by producing a depolarization from which action potentials were triggered. EPSPs could trigger spikes directly or by producing a depolarization that persisted, reaching threshold after the initial peak. $B$, Plot of the effects of all EPSPs from this cell (open circles, individual epochs; filled circle, mean $\pm \mathrm{SD}$ of control ISI) revealed that stimuli before the first spike consistently increased the ISI, whereas stimuli during the first half of the ISI had progressively less effect, and stimuli evoked during the second half of the ISI were excitatory. $C$, Pooled data from seven neurons illustrate that the biphasic effect of intrastriatal stimulation was consistent across the population examined ( filled symbols, mean \pm SD for data binned at 0.1 ISI intervals). Stimuli produced a significant (dotted lines indicate 95\% confidence interval) prolongation or reduction in the ISI, depending on when the stimulus was delivered. $D$, Plot of normalized time between the spike and the EPSP versus the normalized EPSP amplitude for all neurons $(n=7)$ revealed a significant correlation between these two parameters, demonstrating a phase-dependent increase in the EPSP amplitude during the ISI (slope, 0.516; $r=0.382 ; \mathrm{df}=206 ; p<0.001)$.

\section{GABA $_{A}$ receptor-mediated IPSPs produce an apparently phase-independent delay in action potential generation}

The effect of $\mathrm{GABA}_{\mathrm{A}}$ receptor-mediated IPSPs on spike timing was investigated using an analogous protocol to that described above for EPSPs. In neurons in which IPSPs could be evoked, regular spiking was induced by somatic current injections (20-60 pA, $600 \mathrm{msec}, 0.2 \mathrm{~Hz})$, and stimuli (360 $\pm 55 \mu \mathrm{A}, 122 \pm 54 \mu \mathrm{sec})$ were delivered to elicit IPSPs that were of a comparable amplitude (mean, $2.19 \pm 1.46 \mathrm{mV} ; n=5$ ) to EPSPs (Fig. 8). IPSPs produced a prolongation of the ISI $(n=5)$ (Fig. $8 A, B)$ and caused a significant lengthening of the interval between spikes, apparently irrespective of when they occurred during the ISI (Fig. $8 C)$. There was no correlation between when the IPSP was delivered and the effect on the ISI (data not shown) $(r=0.070$; $p>0.2$ ), suggesting that IPSPs were equivalently effective in delaying spike generation, regardless of when they occurred. In contrast, the amplitude of IPSPs as detected at the soma were significantly correlated with both time (slope, 1.096; $r=0.577$; $\mathrm{df}=235 ; p<0.001$ ) (Fig. $8 D$ ) and voltage (slope, $0.067 ; r=$ $0.551 ; \mathrm{df}=235 ; p<0.001$ ) (Fig. $8 E$ ). A $6.7 \%$ change in IPSP amplitude for each millivolt change in membrane potential between -65 and $-45 \mathrm{mV}$ exceeds the predicted $1.7-2.6 \%$ change in IPSP amplitude over this voltage range, calculated on the basis of changes in driving force alone. Furthermore, as the membrane potential at which the IPSPs are evoked becomes more depolarized, the relative change in driving force for each millivolt change in membrane potential declines, but no such change was observed (Fig. 8E). These findings suggest that, in addition to changes in driving force, changes in $R_{\text {in }}$ were also influential in determining the amplitude of the IPSP at the soma. Nevertheless, the amplitude of the IPSP at the soma was not predictive of its efficacy in delaying action potential generation.

\section{Hyperpolarizing somatic current injections exhibit a phase-dependent ability to delay spike initiation}

Brief hyperpolarizing current injections were used to determine whether the effect of synaptic IPSPs on spike timing could be mimicked by voltage perturbations at the soma. Negative current injections $(-1 \mathrm{nA}, 1 \mathrm{msec}$ or $-150 \mathrm{pA}, 10 \mathrm{msec})$ produced a mean hyperpolarization of $10.51 \pm 6.58 \mathrm{mV}(n=2)$ and $6.46 \pm$ $1.39 \mathrm{mV}(n=6)$, respectively, and delayed action potential generation (Fig. 9A). In contrast to synaptic IPSPs, the ability of the brief hyperpolarizations to delay spiking depended on when the pulses were delivered during the ISI $(n=8)$ (Fig. 9B, $C$ ). Examination of the relationship between the time at which hyperpolarizing currents were applied and the ISI revealed a significant (data not shown) $(r=0.436 ; p<0.001)$ positive correlation (slope, 0.253 ) between these parameters, with negative current pulses only producing a significant prolongation in the ISI when delivered $>0.4$ ISI $(\sim 80-120 \mathrm{msec})$ after the first spike. The phase dependence of hyperpolarizing current injections to delay spiking was related to the amplitude of the voltage deflection produced by the current injections at various times during the ISI (Fig. 9D). These parameters were significantly $(r=0.582$; $p<0.001$ ) positively correlated (slope, 0.205 ), confirming that $R_{\text {in }}$ changes during the ISI (see Fig. 9D). However, although plots for the amplitude of the voltage deflection produced by depolarizing (Fig. 6D) and hyperpolarizing (Fig. 9D) current injection versus time both indicate changes in the $R_{\text {in }}$ of cholinergic neurons during the ISI, the slopes from these plots are remarkably discrepant ( 0.790 and 0.205 , respectively), indicating the presence of profoundly nonlinear responses of the membrane during hyperpolarization and depolarization in the subthreshold voltage range.

\section{Stimulus-evoked dopamine release influences spike timing via a D1 receptor-mediated enhancement of the AHP}

After blockade of AMPA, NMDA, and $\mathrm{GABA}_{\mathrm{A}}$ receptors, intrastriatal stimulation failed to evoke detectable synaptic potentials. However, stimuli could still produce a prolongation of the ISI when delivered before or soon after the first spike $(n=13)$ (Fig. $10 A, E$ ), although close examination of the voltage trajectory after stimulation failed to reveal any conductance change associated with the stimulus under these conditions in either current- 
A

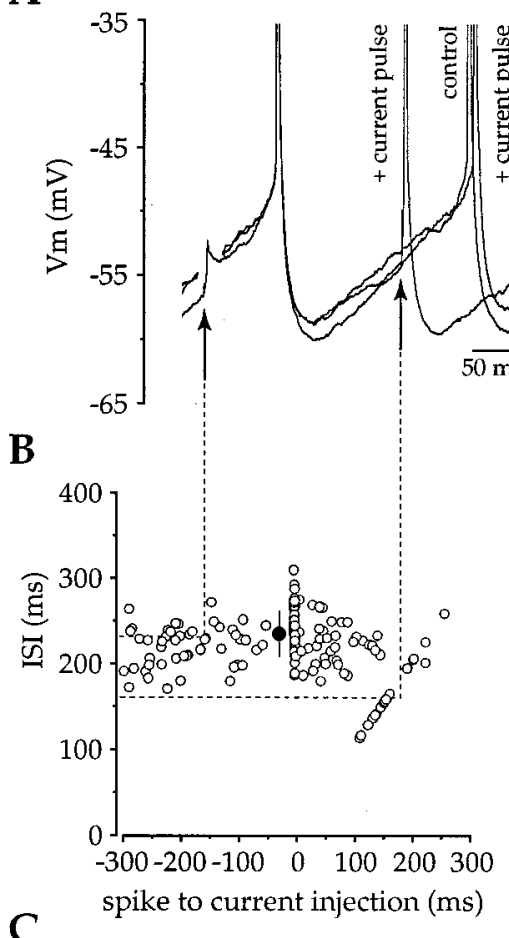

C

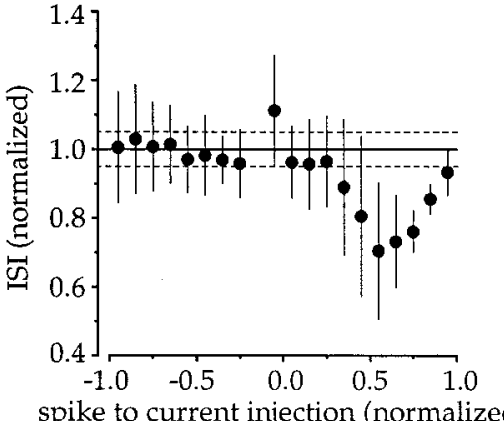

D

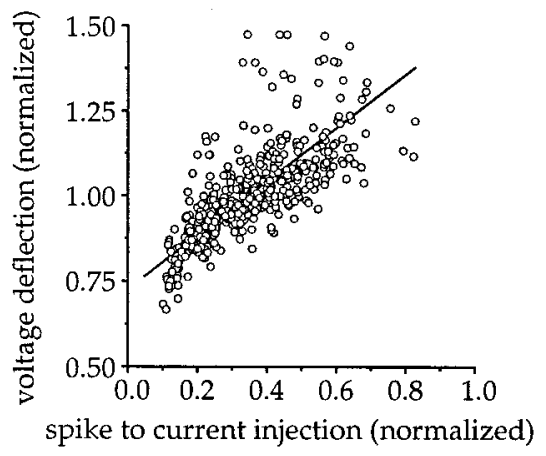

$\mathbf{E}$

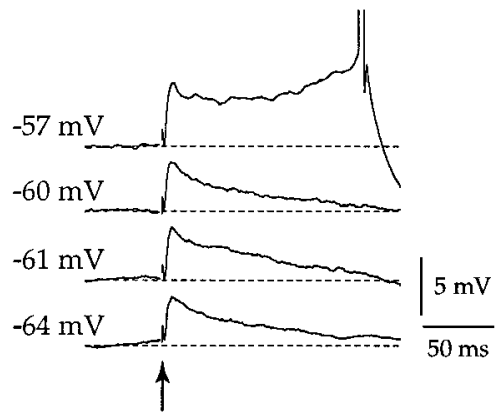

$\mathbf{F}$

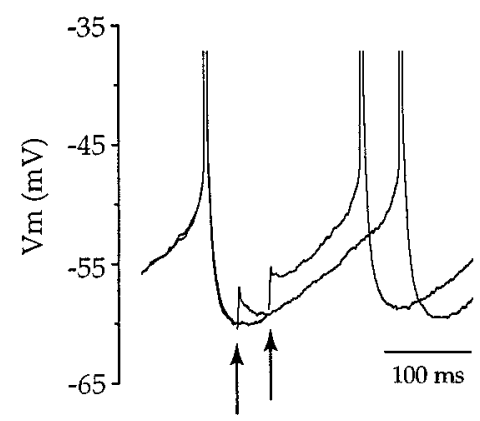

Figure 6. Brief somatic current injections mimic the excitatory actions of EPSPs and reveal changes in $R_{\text {in }}$ during the ISI. $A$, Injection of brief large-amplitude positive current pulses $(0.5 \mathrm{nA}, 1 \mathrm{msec})$ produced membrane depolarizations of an equivalent amplitude to that produced by synaptic EPSPs. Depolarizations before the first spike in a pair did not alter the subsequent ISI, whereas positive current injections in the latter twothirds of the ISI were excitatory and mimicked the actions of EPSPs. $B$, A plot of all epochs from the cell in $A$ confirmed that depolarizing current injections were without effect when given before the first spike but shortened the time between spikes when applied in the latter two-thirds of the ISI. Open circles, Individual epochs; filled circle, mean $\pm \mathrm{SD}$ of control ISI. $C$, Examination of pooled data $(n=12)$ revealed that these effects were consistent across the population, with only the excitatory effects present when depolarizing current injections were delivered during the latter two-thirds of the ISI ( filled symbols, mean \pm SD for data binned at 0.1 ISI; dotted lines are $95 \%$ confidence intervals). $D$, Plot of phase of the current injection versus the normalized voltage deflection revealed large changes in the apparent input resistance of the neuron during the ISI (slope, $0.790 ; r=0.729 ; \mathrm{df}=451 ; p<0.001) . E, F$, Both EPSPs $(E)$ and voltage deflections produced by current injections $(F)$ elicit voltage-dependent prolonged depolarizations, indicative of the recruitment of a subthreshold regenerative inward current. clamp or voltage-clamp recordings $(n=13)($ Fig. $10 B-D)$. However, the voltage-clamp recordings were made with the electrode solution that contained cesium and QX-314, and consequently the majority of sodium and potassium currents should have been blocked (Hagiwara et al., 1976; Adelman and French, 1978; Nathan et al., 1990). Short trains of stimuli were also applied but did not evoke any short latency synaptic response but produced a long slow depolarization, as has been shown by Aosaki and Kawaguchi (1996) to result from the release of substance P. Prespike stimuli also failed to produce any detectable alteration of spike threshold, action potential amplitude, or spike width $(n=$ 8). However, stimuli delivered before or soon after the first spike consistently enhanced the amplitude and duration of the spike AHP $(n=13)$ (Fig. 10A). Together, these data suggest that the prolongation of the ISI produced by stimuli delivered before or soon after a spike are not caused by direct activation of an ionic conductance but instead reflect the action of a neuromodulator that enhances the AHP. Previous experiments have demonstrated that activation of D1 dopamine receptors can facilitate L-type calcium currents (Surmeier et al., 1995) and enhance the AHP in neostriatal spiny neurons (Hernandez-Lopez et al., 1996). We therefore conducted a series of experiments to determine whether D1 dopamine receptor activation might underlie the stimulus-induced prolongation of the ISI. In the presence of APV, DNQX and BMI stimuli $(213 \pm 80 \mu \mathrm{A}, 79 \pm 26 \mu \mathrm{sec})(n=$ $8)$ produced a significant increase in the ISI when delivered before or soon after the first spike $(n=8)$ (Fig. 10A,E). Application of SCH-23390 $(10 \mu \mathrm{M})$ prevented the stimulus-induced enhancement of the ISI $(n=7)$ (Fig. $10 E)$ by blocking D1 dopamine receptor-mediated modulation of the amplitude and time course of the AHP. A two-way ANOVA revealed a significant difference in the ISI before and after drug application $(F=$ 19.65; df $=1,1276 ; p<0.01)$ and demonstrated a significant phase-dependent interaction $(F=2.33$; df $=19,1276 ; p<0.01)$. The prolongation of the ISI by stimuli delivered at very early intervals appears not to have been blocked by SCH-23390 (Fig. $10 E$ ), suggesting that this effect is not mediated by D1 receptors but may result from D2 receptor activation or the action of another neuromodulator. The D1 dopamine receptor-mediated enhancement of the AHP provides an explanation for the paradoxical ability of EPSPs to cause a prolongation of the ISI when delivered before or soon after a spike (Fig. $5 A-C$ ) and may also be responsible, at least during the early portion of the ISI, for the apparent phase-independent ability of IPSPs to delay spike generation (Fig. $8 A-C$ ). 
A B
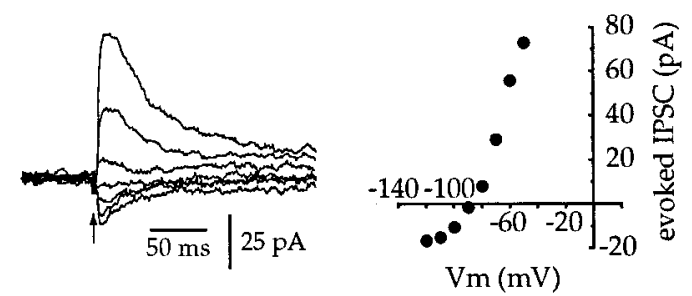

C

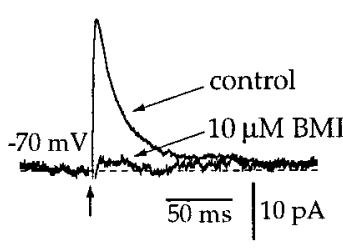

D

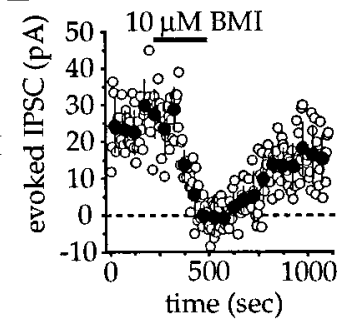

Figure 7. Current-voltage and pharmacological characterization of inhibitory synaptic inputs to cholinergic cells. $A$, After blockade of AMPA and NMDA receptors, intrastriatal stimulation at holding potentials between -120 and $-60 \mathrm{mV}$ evoked a voltage-dependent IPSC. Each trace is an individual IPSC. $B$, Current-voltage relationship for the cell in $A$. Each point represents the mean of three IPSCs evoked at each holding potential and indicates a reversal potential of approximately $-88 \mathrm{mV}$, which is consistent with the value predicted by the Nernst equation. $C$, Application of $10 \mu \mathrm{M}$ bicuculline completely blocked the evoked IPSC. Traces are averages of 30-50 individual IPSCs. $D$, Time series from the same cell in $C$ illustrates a reversible blockade of the evoked IPSCs after application and washout of bicuculline (open circles, individual IPSCs; filled circles, mean \pm SD of six sequential IPSCs).

\section{DISCUSSION}

These data demonstrate that neostriatal cholinergic interneurons receive $\mathrm{AMPA}, \mathrm{GABA}_{\mathrm{A}}$, and $\mathrm{D} 1$ receptor-mediated synaptic inputs, which influence spike timing in surprisingly different ways. AMPA inputs exhibit a phase-dependent efficacy and are ineffective during the first third of the ISI but can tightly regulate spike generation during the latter two-thirds of the ISI, indicating that they are likely to control the precise patterning of action potentials in cholinergic interneurons. Conversely, IPSPs appear to inhibit firing in a phase-independent manner and probably influence the overall level of excitability. Additionally, D1 receptor-mediated enhancement of the AHP delays spike generation and may underlie the pause in firing observed in TANs in vivo in response to sensory stimuli, which serve as a cue to perform a learned motor task.

\section{AMPA receptor-mediated synaptic depolarizations shorten the ISI, up to a point}

Isolated AMPA receptor-mediated EPSPs that were evoked during the first third of the ISI did little to influence spike timing, but EPSPs triggered later in the ISI became progressively more effective, exhibiting maximal efficacy between 0.6 and 0.8 ISI after the first spike. The ability of EPSPs to trigger spikes during the early phase of the ISI is probably somewhat underestimated, because the depolarization is opposed by the D1 dopamine receptor-mediated enhancement of the AHP (see below). Nevertheless, when brief depolarizing current injections were used to produce somatic voltage deflections of a similar amplitude to synaptically evoked EPSPs, the ISI shortening effects of the EPSPs were reproduced. The current injections also revealed very

large changes in the apparent $R_{\text {in }}$ during the ISI. The $R_{\text {in }}$ is one of the principal determinants of the amplitude and time course of voltage deflections produced by synaptically or artificially injected currents (Rall, 1977). The fact that both EPSPs and voltage deflections caused by current injections could also produce persistent depolarizations is suggestive of the recruitment of a subthreshold inward current. Similar persistent depolarizations after EPSPs have been described in both neostriatal spiny neurons (Kawaguchi et al., 1989) and in neocortical cells (Reyes and Fetz, 1993) and are thought to arise from the activation of a subthreshold persistent sodium current (Reyes and Fetz, 1993). Cholinergic interneurons also possess a persistent sodium current (Chao and Alzheimer, 1995), which probably contributes to the long-lasting depolarization seen after subthreshold EPSPs and provides an explanation for the discrepancy in the apparent $R_{\mathrm{in}}$ inferred from the amplitude of the voltage deflections produced by hyperpolarizing and depolarizing current pulses delivered during the ISI.

Previous experiments have shown that cholinergic interneurons are recipients of both AMPA and NMDA receptormediated synaptic inputs (Jiang and North, 1991; Kawaguchi, 1992), which are thought to arise from the cortex and thalamus (Wilson et al., 1990; Lapper and Bolam, 1992) and to be responsible for the barrage of depolarizing synaptic potentials observed during intracellular recordings in vivo (Wilson et al., 1990). The data presented in this study predict that the tonic irregular firing pattern observed in cholinergic cells in vivo is an entrainment of the neuron to the pattern of incoming depolarizing synaptic potentials. However, a ceiling is set on the firing rate by the AHP, which serves to veto excitatory inputs arriving during the first third of the ISI. The ability of subsequent depolarizing inputs arriving during the latter two-thirds of the ISI to influence spike timing depends on the $R_{\text {in }}$ of the neuron, which is primarily determined by the AHP, and whether the subthreshold regenerative current is activated.

\section{$\mathrm{GABA}_{\mathrm{A}}$ receptor-mediated synaptic inputs delay spike} initiation independently of their somatic amplitude

Although cholinergic interneurons are known to receive GABAcontaining synaptic inputs (Bolam, 1989) and to be responsive to direct application of GABA (Yan et al., 1997), no physiological data on the characteristics or effects of synaptically evoked inhibitory inputs to these cells has been documented. The data presented here indicate that cholinergic interneurons are recipients of a relatively sparse inhibitory input that is mediated by $\mathrm{GABA}_{\mathrm{A}}$ receptors, which can influence spike timing. The IPSPs evoked by intrastriatal stimulation may arise from local axon collaterals of spiny neurons (Bolam et al., 1986; Martone et al., 1992) and possibly from GABAergic interneurons, although there is as yet no anatomical evidence for the latter. The IPSPs appear to produce a prolongation of the ISI, irrespective of when they occur, which is surprising in light of the fact that the amplitude of the evoked IPSPs detected at the soma were strongly influenced by both the $R_{\text {in }}$ and the driving force. However, the D1-mediated enhancement of the AHP may have contributed to the apparent efficacy of IPSPs evoked during the early phase of the ISI. Nevertheless, IPSPs exhibited a phase-independent ability to delay spiking in the second half of the ISI, although the D1 receptor-mediated effect is absent during this phase of the ISI. The inhibitory inputs seem to be directed predominantly to distal regions of cholinergic cells, because the slopes for the amplitude of the voltage deflections produced by intrasomatic hyperpolarizing current injections and IPSPs at various times during the ISI 
A
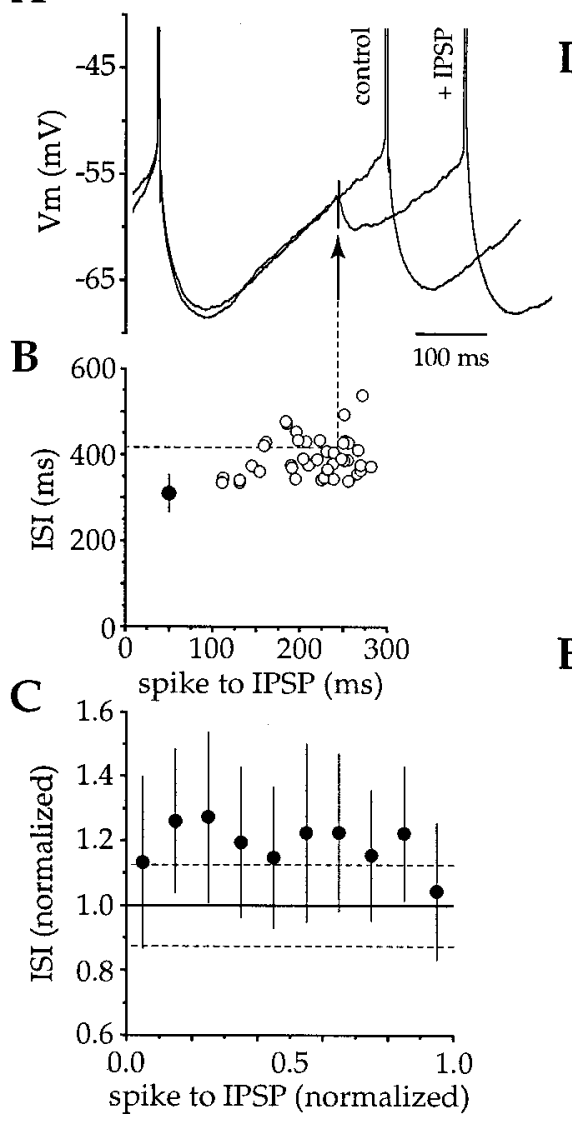

D

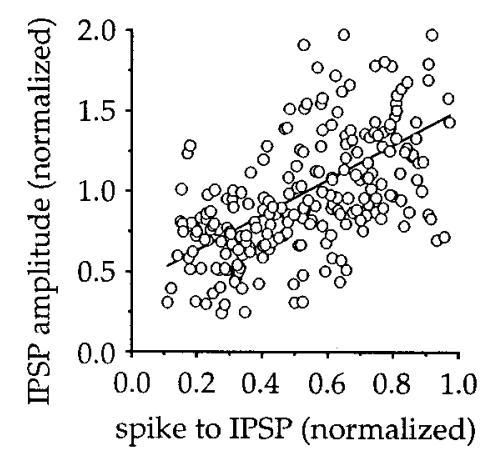

$\mathbf{E}$

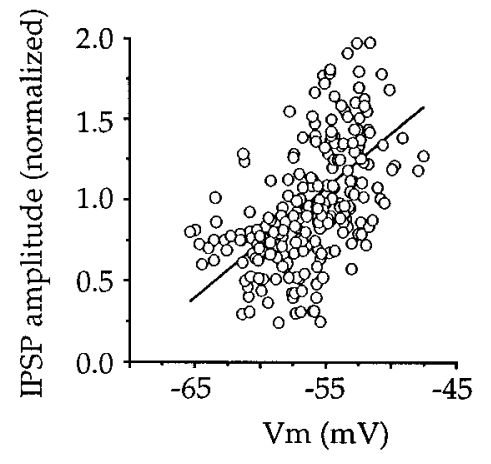

Figure 8. IPSPs produce a phase-independent prolongation of the ISI. $A$, Intrastriatal stimulation after blockade of AMPA and NMDA receptors elicited a GABA receptor-mediated IPSP that delayed the subsequent spike. $B$, The ability of the IPSP to increase the ISI was independent of when the IPSP occurred during the ISI (open circles, individual epochs; filled circle, mean $\pm \mathrm{SD}$ of control ISI). $C$, Examination of five neurons revealed that synaptically evoked IPSPs produced a prolongation of the ISI, irrespective of when the IPSP occurred during the ISI ( filled circles, mean \pm SD binned at 0.1 ISI; dotted lines indicate $95 \%$ confidence limits). $D, E$, Plots of normalized time from the spike to the IPSP versus the normalized IPSP amplitude (slope, 1.096; $r=$ $0.577 ; \mathrm{df}=235 ; p<0.001)$ or membrane potential at which the IPSP was evoked (slope, $0.067 ; r=0.551 ; \mathrm{df}=$ 235; $p<0.001)$. These data revealed the amplitude of the IPSP, as detected at the soma, was strongly dependent on when the IPSP occurred during the ISI.

A

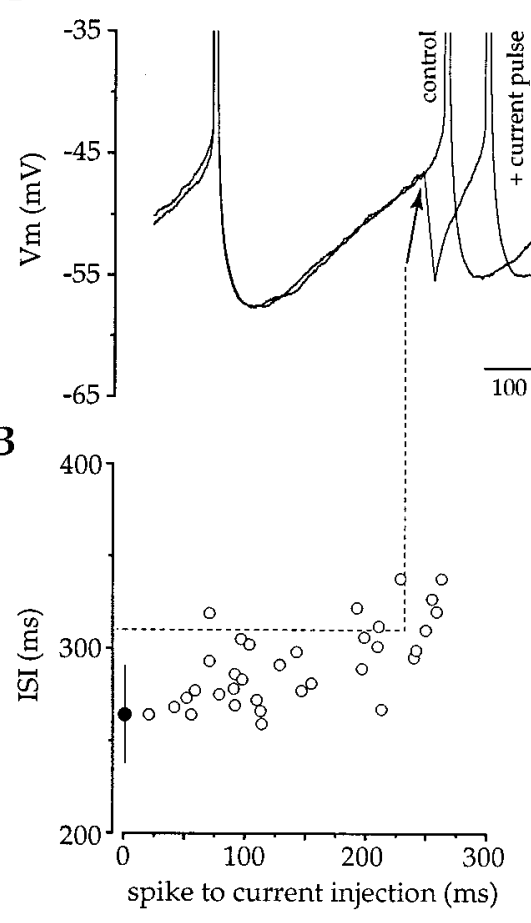

C
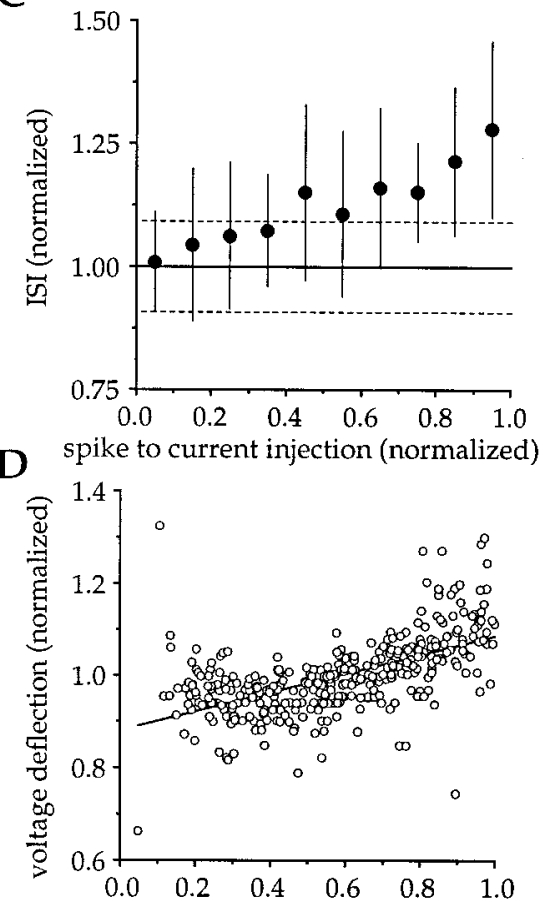

spike to current injection (normalized)
Figure 9. Brief somatic hyperpolarizations delay spiking and confirm that $R_{\text {in }}$ changes during the ISI. $A$, Injection of large-amplitude brief-duration negative current ( $-1 \mathrm{nA}, 1 \mathrm{msec}$ ) produced a membrane hyperpolarization and delayed action potential generation. $B$, Examination of all epochs from the same cell in $A$ demonstrated that the efficacy of somatic hyperpolarizations in delaying spiking were dependent on when the pulse was delivered during the ISI (open circles, individual epochs; filled circle, mean \pm SD of control ISI). $C$, Pooled data $(n=8)$ illustrate that the efficacy of somatic hyperpolarization in delaying spike generation was observed across the population ( filled circles, mean \pm SD binned at 0.1 ISI; dotted lines indicate $95 \%$ confidence intervals). $D$, Plot of data from all cells for the relationship between phase and normalized voltage deflection illustrates the change in $R_{\text {in }}$ taking place during the ISI (slope, 0.205; $r=0.582$; df $=347 ; p<0.001$ ). 
Figure 10. Prolongation of the ISI is attributable to D1 dopamine receptor-mediated enhancement of the AHP. A, A family of traces from a single neuron in which stimuli were delivered before the first spike in the presence of DNQX, APV, and BMI (gray) or no stimulus was given (black). Arrow indicates the mean ISI in each case. The stimulus causes a prolongation of the ISI by increasing the amplitude and duration of the AHP. $B$, An enlarged trace illustrates an EPSP evoked in the same neuron as in $A$, before application of DNQX. $C$, After blockade of the evoked AMPA receptor-mediated EPSP with DNQX (20 $\mu \mathrm{M})$ and in the presence of BMI $(10 \mu \mathrm{M})$ and APV $(50 \mu \mathrm{M})$, the same stimulus fails to evoke any detectable synaptic response. $D$, Stimuli applied over a large range of membrane potentials in voltage-clamp recordings confirm that in the presence of DNQX, APV, and BMI no detectable conductance change is induced by intrastriatal stimulation. Recording in $D$ made with a cesium and QX-314-containing electrode solution. $E$, Intrastriatal stimuli presented before or soon after a spike caused a prolongation of the ISI in the presence of APV, BMI, and DNQX $(n=8)$ ( filled symbols). The prolongation was blocked by application of $10 \mu \mathrm{M}$ $\mathrm{SCH}-23390(n=7)$ (open symbols), a D1 receptor antagonist (symbols, mean \pm SD for data binned at 0.1 ISI intervals; dotted lines indicate $95 \%$ confidence limits).
A

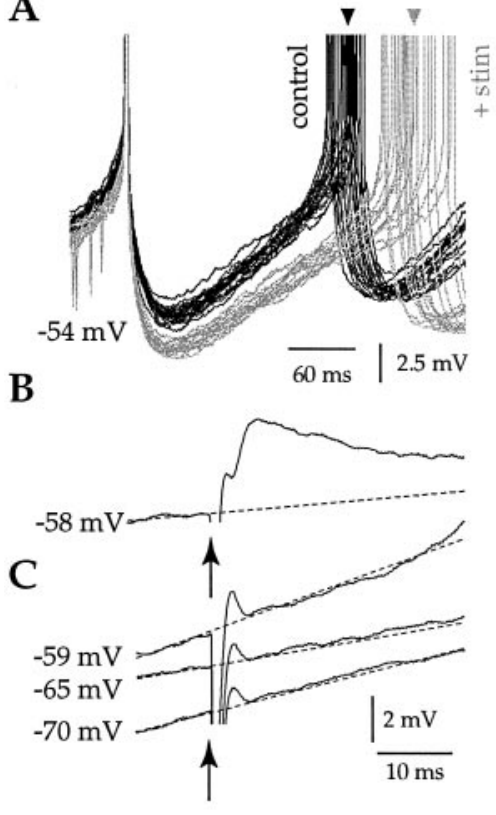

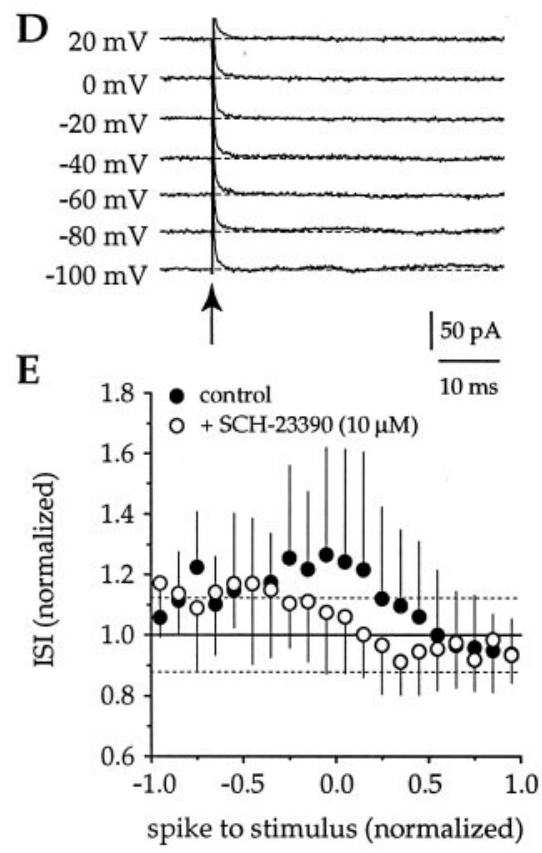

are 0.205 and 1.096, respectively. Although there is a considerable change in driving force for IPSPs over the subthreshold voltage range, this is not sufficient to account for a fivefold difference in slope and therefore indicates that the current injected by inhibitory synapses is shunted more effectively than hyperpolarizing currents injected at the soma. These data predict that IPSPs would serve to reduce the firing rate of cholinergic neurons, but unlike EPSPs, the inhibitory inputs seem unsuitable for tight regulation of the firing pattern.

\section{Spike-timing is influenced by D1 receptor-mediated modulation of the AHP}

Stimuli delivered before a spike or soon thereafter lengthened the subsequent ISI in cholinergic cells even after AMPA, NMDA, and $\mathrm{GABA}_{\mathrm{A}}$ receptors had been blocked and all detectable conductance changes had been abolished. Furthermore, stimuli did not alter spike threshold, width, or amplitude but did enhance the AHP. Because the AHP in cholinergic neurons results from activation of a calcium-dependent potassium current (Kawaguchi, 1993), the most parsimonious explanation is that the stimulus caused release of a neuromodulator, which enhanced calcium entry during the spike. Previous studies have demonstrated that activation of D1 dopamine receptors can increase L-type calcium currents (Surmeier et al., 1995) and enhance the AHP in neostriatal spiny cells (Hernandez-Lopez et al., 1996). The stimulusinduced increase in the ISI in cholinergic interneurons was blocked by SCH-23390, indicating that evoked release of dopamine, acting via D1 receptors, was responsible for the enhanced AHP. Although modulation of spike-dependent calcium entry provides a likely explanation for the D1-mediated effect, clearly there are also additional D1 effects, because postspike stimuli could also increase the duration of the ISI. Recently, D1 receptor stimulation has been demonstrated to cause activation of a mixed cation conductance in a subpopulation of neostriatal cholinergic interneurons (Aosaki et al., 1998), which might cause calcium entry and a subsequent prolongation of the AHP. However, we were unable to detect such a conductance change after intrastriatal stimuli.
An interaction between cholinergic and dopaminergic systems was originally proposed on the basis of clinical investigations of Parkinson's disease (McGeer et al., 1961; Barbeau, 1962). Subsequent studies have demonstrated that neostriatal cholinergic interneurons are recipients of dopaminergic input (Kubota et al., 1987), express $D_{1 b}$ and $D_{2}$ dopamine receptors (Yan and Surmeier, 1997), and are responsive to D1 (Aosaki et al., 1998) and D2 (Yan and Surmeier, 1997) receptor agonists. Our data provide a physiological basis for the ability of dopamine to influence acetylcholine release via the alteration of spike timing by a D1 receptor-mediated modulation of the AHP.

\section{Implications for spike timing in TANs}

In awake behaving monkeys, it is clear that TANs respond to sensory cues that serve as stimuli to perform a reward-driven motor task (Graybiel et al., 1994; Aosaki et al., 1995). The pause in the tonic firing pattern observed in response to behaviorally relevant sensory stimuli requires that the dopaminergic input to the neostriatum is intact (Aosaki et al., 1994a; Watanabe and Kimura, 1998). Our data suggest that a D1 receptor-mediated enhancement of the AHP may be directly responsible for the pause, at least during the early phase of task acquisition when dopaminergic neurons of the midbrain are firing in response sensory cues (Schultz et al., 1997). Furthermore, we conclude that the synaptic barrage seen in cholinergic neurons in vivo is likely to predominantly reflect a high frequency of AMPA receptormediated synaptic inputs that interact dynamically with the intrinsic membrane properties of cholinergic neurons to precisely pattern action potential timing. Finally, IPSPs appear to be unsuitable for precise spike timing and instead probably influence the overall firing rate.

\section{REFERENCES}

Adelman Jr WJ, French RJ (1978) Blocking of the squid axon potassium channel by external caesium. J Physiol (Lond) 276:13-25.

Agard DA, Hiraoka Y, Shaw P, Sedat JW (1989) Fluorescence microscopy in three dimensions. Methods Cell Biol 30:353-377.

Aosaki T, Kawaguchi Y (1996) Actions of substance P on rat neostriatal neurons in vitro. J Neurosci 16:5141-5153. 
Aosaki T, Graybiel AM, Kimura M (1994a) Effect of the nigrostriatal dopamine system on acquired neural responses in the striatum of behaving monkeys. Science 265:412-415.

Aosaki T, Tsubokawa H, Ishida A, Watanabe K, Graybiel AM, Kimura M (1994b) Responses of tonically active neurons in the primate's striatum undergo systematic changes during behavioral sensorimotor conditioning. J Neurosci 14:3969-3984.

Aosaki T, Kimura M, Graybiel AM (1995) Temporal and spatial characteristics of tonically active neurons of the primate's striatum. J Neurophysiol 73:1234-1252.

Aosaki T, Kiuchi K, Kawaguchi Y (1998) Dopamine $\mathrm{D}_{1}$-like receptor activation excites rat striatal large aspiny neurons in vitro. J Neurosci 18:5180-5190.

Apicella P, Scarnati E, Schultz W (1991) Tonically discharging neurons of monkey striatum respond to preparatory and rewarding stimuli. Exp Brain Res 84:672-675.

Barbeau A (1962) The pathogenesis of Parkinson's disease: a new hypothesis. Can Med Assoc J 87:802-807.

Bolam JP (1989) Cholinergic neurons in the striatum and basal forebrain receive direct synaptic input from GABA-containing axon terminals. Neurosci Lett Suppl 36:S9.

Bolam JP, Wainer BH, Smith AD (1984) Characterization of cholinergic neurons in the rat neostriatum. A combination of choline acetyltransferase immunocytochemistry, Golgi-impregnation and electron microscopy. Neuroscience 12:711-718.

Bolam JP, Ingham CA, Izzo PN, Levey AI, Rye DB, Smith AD, Wainer BH (1986) Substance P-containing terminals in synaptic contact with cholinergic neurons in the neostriatum and basal forebrain: a double immunocytochemical study in the rat. Brain Res 397:279-289.

Chao TI, Alzheimer C (1995) Do neurons from rat neostriatum express both a TTX-sensitive and a TTX-insensitive slow $\mathrm{Na}^{+}$current? J Neurophysiol 74:934-941.

Crutcher MD, DeLong MR (1984) Single cell studies of the primate putamen. II. Relations to direction of movement and pattern of muscular activity. Exp Brain Res 53:244-258.

DiFiglia M (1987) Synaptic organization of cholinergic neurons in the monkey neostriatum. J Comp Neurol 255:245-258.

Götz T, Kraushaar U, Geiger J, Lubke J, Berger T, Jonas P (1997) Functional properties of AMPA and NMDA receptors expressed in identified types of basal ganglia neurons. J Neurosci 17:204-215.

Graybiel AM, Aosaki T, Flaherty AW, Kimura M (1994) The basal ganglia and adaptive motor control. Science 265:1826-1831.

Hagiwara S, Miyazaki NP, Rosenthal NP (1976) Potassium current and the effect of cesium on this current during anomalous rectification of the egg cell membrane of a starfish. J Gen Physiol 67:621-638.

Hernandez-Lopez S, Bargas J, Reyes A, Galarraga E (1996) Dopamine modulates the afterhyperpolarization in neostriatal neurones. NeuroReport 31:454-456.

Hikosaka O, Sakamoto M, Usui S (1989) Functional properties of monkey caudate neurons. I. Activities related to saccadic eye movements. J Neurophysiol 61:780-798.

Horikawa K, Armstrong WE (1988) A versatile means of intracellular labeling: injection of biocytin and its detection with avidin conjugates. J Neurosci Methods 25:1-11.

Jiang ZG, North RA (1991) Membrane properties and synaptic responses of rat striatal neurones in vitro. J Physiol (Lond) 443:533-553.

Kawaguchi Y (1992) Large aspiny cells in the matrix of the rat neostriatum in vitro: physiological identification, relation to the compartments and excitatory postsynaptic currents. J Neurophysiol 67:1669-1682.

Kawaguchi Y (1993) Physiological, morphological, and histochemical characterization of three classes of interneurons in rat neostriatum. J Neurosci 13:4908-4923.

Kawaguchi Y, Wilson CJ, Emson PC (1989) Intracellular recording of identified neostriatal patch and matrix spiny cells in a slice preparation preserving cortical inputs. J Neurophysiol 62:1052-1068.

Kimura M, Rajkowski J, Evarts E (1984) Tonically discharging putamen neurons exhibit set-dependent responses. Proc Natl Acad Sci USA 81:4998-5001.
Kimura M, Kato M, Shimazaki H (1990) Physiological properties of projection neurons in the monkey striatum to the globus pallidus. Exp Brain Res 82:672-676.

Kimura M, Kato M, Shimazaki H, Watanabe K, Matsumoto N (1996) Neural information transferred from the putamen to the globus pallidus during learned movement in the monkey. J Neurophysiol 76:3771-3786.

Kubota Y, Inagaki S, Shimada S, Kito S, Eckenstein F, Tohyama M (1987) Neostriatal cholinergic neurons receive direct synaptic inputs from dopaminergic axons. Brain Res 413:179-184.

Lapper SR, Bolam JP (1992) Input from the frontal cortex and the parafascicular nucleus to cholinergic interneurons in the dorsal striatum of the rat. Neuroscience 51:533-545.

Liles SL (1985) Activity of neurons in putamen during active and passive movements of wrist. J Neurophysiol 53:217-236.

Martone ME, Armstrong DM, Young SJ, Groves PM (1992) Ultrastructural examination of enkephalin and substance $\mathrm{P}$ input to cholinergic neurons within the rat neostriatum. Brain Res 594:253-262.

McGeer PL, Boulding JE, Gibson WC, Foulkes RG (1961) Druginduced extrapyramidal reactions. J Am Med Assoc 177:665-670.

Nathan T, Jensen MS, Lambert JD (1990) The slow inhibitory postsynaptic potential in rat hippocampal CA1 neurones is blocked by intracellular injection of QX-314. Neurosci Lett 110:309-313.

Phelps PE, Houser CR, Vaughn JE (1985) Immunocytochemical localization of choline acetyltransferase within the rat neostriatum: a correlated light and electron microscopic study of cholinergic neurons and synapses. J Comp Neurol 238:286-307.

Plenz D, Aertsen A (1996) Neural dynamics in cortex-striatum cocultures. I. Anatomy and electrophysiology of neuronal cell types. Neuroscience 70:861-891.

Rall W (1977) Core conductor theory and cable properties of neurons. In: Handbook of physiology, Sec 1, The nervous system (Kandel ER, ed), pp 39-97. Bethesda, MD: American Physiological Society.

Reyes AD, Fetz EE (1993) Two modes of interspike interval shortening by brief transient depolarizations in cat neocortical neurons. J Neurophysiol 69:1661-1672.

Schultz W, Romo R (1988) Neuronal activity in the monkey striatum during the initiation of movements. Exp Brain Res 71:431-436.

Schultz W, Dayan P, Montague PR (1997) A neural substrate of prediction and reward. Science 275:1593-1599.

Stuart GJ, Dodt HU, Sakmann B (1993) Patch-clamp recordings from the soma and dendrites of neurons in brain slices using infrared video microscopy. Pflügers Arch 423:511-518.

Surmeier DJ, Bargas J, Hemmings HC, Nairn AC, Greengard P (1995) Modulation of calcium currents by a $\mathrm{D}_{1}$ dopaminergic protein kinase/ phosphatase cascade in rat neostriatal neurons. Neuron 14:385-397.

Wainer BH, Bolam JP, Freund TF, Henderson Z, Totterdell S, Smith AD (1984) Cholinergic synapses in the rat brain: a correlated light and electron microscopic immunohistochemical study employing a monoclonal antibody against choline acetyltransferase. Brain Res 308:69-76.

Watanabe K, Kimura M (1998) Dopamine receptor-mediated mechanisms involved in the expression of learned activity of primate striatal neurons. J Neurophysiol 79:2568-2580.

Wilson CJ (1993) The generation of natural firing patterns in neostriatal neurons. In: Chemical signalling in the basal ganglia, Progress in brain research 99, pp 277-297. Oxford: Elsevier.

Wilson CJ, Chang HT, Kitai ST (1990) Firing patterns and synaptic potentials of identified giant aspiny interneurons in the rat neostriatum. J Neurosci 10:508-519.

Yan Z, Surmeier DJ (1997) D5 dopamine receptors enhance Zn2+sensitive GABA(A) currents in striatal cholinergic interneurons through a PKA/PP1 cascade. Neuron 19:1115-1126.

Yan Z, Song WJ, Surmeier J (1997) D2 dopamine receptors reduce N-type $\mathrm{Ca} 2+$ currents in rat neostriatal cholinergic interneurons through a membrane-delimited, protein-kinase-C-insensitive pathway. J Neurophysiol 77:1003-1015. 